Gut, 1987, 28, S1, 197-201

\title{
Effect of experimental pancreatic growth on the content of xenobiotic-metabolising enzymes in the pancreas
}

\author{
J ROSS, AND J A BARROWMAN \\ From the Faculty of Medicine, Memorial University of Newfoundland, St. John's, Newfoundland, Canada
}

SUMMARY The concentration in pancreatic tissue and the total pancreatic content of three xenobiotic metabolising enzymes has been determined in two models of experimental pancreatic growth namely, cholecystokinin-octapeptide injections and soy flour feeding. No significant change in pancreatic concentrations of benzo(a)pyrene hydroxylase or glucuronyl transferase was detected. In both models of pancreatic growth, however, the concentration of glutathione-S-transferase was significantly reduced. It is possible that the reduction in this enzyme may be of some importance in determining the susceptibility of the pancreas to carcinogenesis observed with long term soy flour feeding.

Injections of cholecystokinin (CCK) and its synthetic analogues and the feeding of raw soya flour or soy bean trypsin inhibitor are potent stimuli for pancreatic growth in several species. ${ }^{12}$ There is some evidence that the trophic response of the rat pancreas to soy flour feeding is, at least in part, mediated by the release of increased amounts of endogenous CCK produced by intraluminal inhibition of tryptic activity in the intestine by the soy bean trypsin inhibitor. ${ }^{34}$ Soy flour feeding in conjunction with the feeding of azaserine, a weak pancreatic carcinogen ${ }^{5}$ enhances the yield of malignant tumours in these animals as compared with the feeding of the carcinogen alone. ${ }^{6}$ It has also been observed, however, that prolonged feeding of raw soya flour to rats results in development of adenomatous nodules in the pancreas and oltimately pancreatic carcinomas. ${ }^{7}$

While the prolonged stimulus may, by itself, lead to ihe development of carcinomas, one possible mechanism may involve modification of the ability of the pancreas to handle the low background levels of carcinogenic xenobiotics present in the environment, most importantly, in the diet. Over a prolonged period of time, a small change in the capability of the pancreas to handle such compounds might be important in the development of malignant change in the gland. To study this, we have examined the ability of the control and hypertrophic pancreas of rats to

Address for correspondence: Dr J Ross, Faculty of Medicine, Memorial Univ. of Newfoundland, St John's, Newfoundland, Canada A1B 3V6 carry out phase I (arylhydrocarbon hydroxylase) and phase II (glucuronyl transferase and glutathione-Stransferase) reactions.

\section{Methods}

\section{ANIMALS}

Adult male Sprague-Dawley rats, purchased from Canada Hybrid Farms, NS were maintained, four to a cage, at a minimum $40 \%$ relative humidity, approximately $23{ }^{\circ} \mathrm{C}, 12: 12$ photoperiod and provided with food and water ad libitum until killed.

\section{TREATMENT}

In one experiment two rats $(200-300 \mathrm{~g}$ when first injected) in each cage received twice daily subcutaneous injections of cholecystokinin-octapeptide (CCK-OP) (Kinevac $300 \mathrm{ng} / 100 \mathrm{~g} /$ day) for 14 days while the other two were similarly injected with sterile $0.9 \% \mathrm{NaCl}$. Animals were fed Rat $\mathrm{Chow}^{(\mathrm{R})}$ (Ralston Purina Co.).

In the other experiment half the rats $(120-200 \mathrm{~g})$ were maintained for 28 days in a pelleted feed (Ralston Purina Co, Richmond, Ind.) containing $40 \%$ raw defatted soya flour while the other half were provided with pellets identical except that the soya flour had been toasted to inactivate most of the trypsin inhibitor (TI) activity (reduced from 29.5 to $5 \mathrm{mg} \mathrm{TI} / \mathrm{g}$ ). 


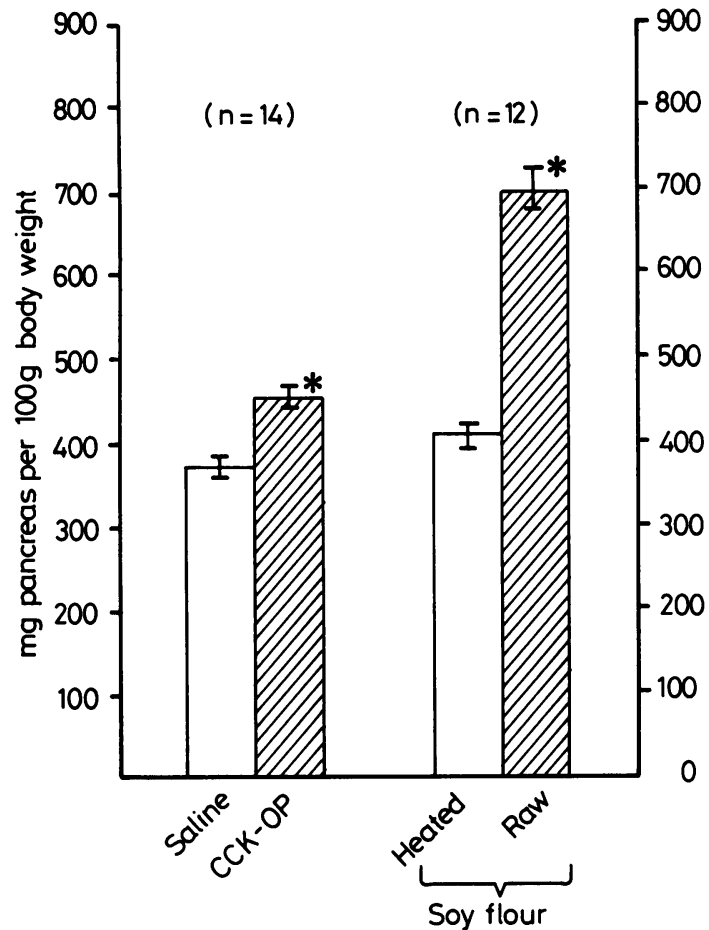

Fig. 1 Pancreatic weights (means $\pm S E M$ ) of rats treated with cholecystokinin-octapeptide or fed soy flour diets * indicates $p<0.05$.

\section{CELL FRACTIONATION}

Cell fractionation was carried out using standard methods. ${ }^{89}$ The pancreas was quantitatively freed from the surrounding tissues and transferred to iced $0.9 \%$ saline where adhering fat, connective tissue and major blood vessels were removed. Excess fluid was removed by pressing the tissue between two layers of filter paper (Canlab F-2402) under a $200 \mathrm{~g}$ weight for 20 seconds. After weighing, the tissue was transferred to $25 \mathrm{ml}$ of cold $50 \mathrm{mM}$ Tris, $\mathrm{pH} 7.5$, containing $0.25 \mathrm{M}$ sucrose. All remaining steps were performed at $0-4{ }^{\circ} \mathrm{C}$. The tissue was homogenised using a motor driven Teflon pestle for six strokes. The supernatant from sequential $650 \mathrm{~g}$ and $10000 \mathrm{~g} \mathrm{10-min}$. centrifugation was centrifuged at $105000 \mathrm{~g}$ in an angle headed rotor for one hour. The 'microsomal' pellet was resuspended in $9 \mathrm{ml}$ of buffer/sucrose by homogenising six strokes. Samples were frozen in liquid nitrogen and stored at $-70^{\circ} \mathrm{C}$.

\section{ENZYME ASSAYS}

Microsomal mono-oxygenase (BPH) activity was determined by measuring the water soluble metabolites produced during 15 minutes incubation with radioactive benzo(a)pyrene (unmetabolised BP was

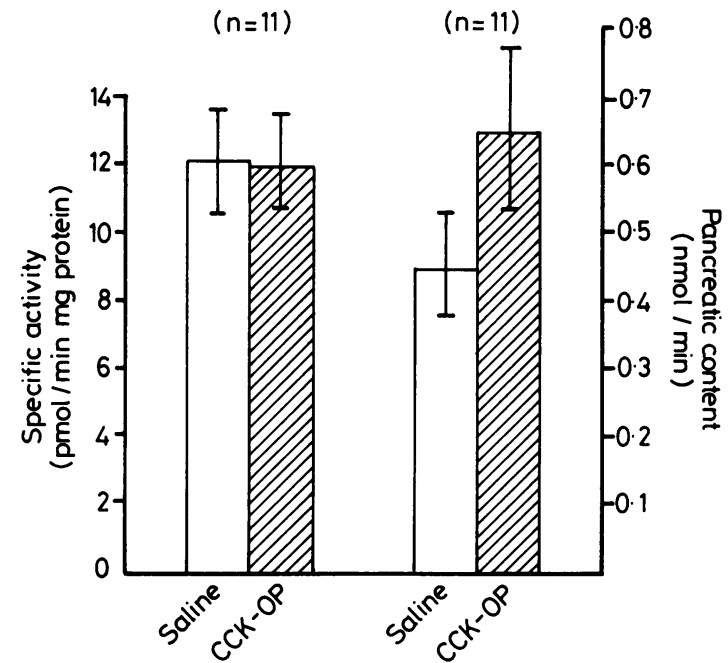

Fig. 2 Benzo(a)pyrene hydroxylase pancreatic concentration and total content cholecystokinin-octapeptide treatment. ${ }^{*}$ indicates $p<0.05$.

extracted using ethyl acetate: acetone).$^{1011}$ Microsomal glucuronyltransferase (GT) activity was measured using radioactive l-naphthol as substrate. ${ }^{12}$ Glutathione-S-transferase (GSH-T) activity in the $105000 \mathrm{~g}$ supernatant ('cystosol') was measured spectrophotometrically using 1-chloro-2,4-dinitrobenzene as substrate. ${ }^{13}$ Protein concentrations were measured using the Biorad Protein Assay. Microsomal mono-oxygenase (BPH) GT and GSH-T activities were measured in $10 \mathrm{mM}$ phosphate buffer, $\mathrm{pH} \mathrm{7.4 \text {,containing } 1 . 1 \mathrm { mM } \mathrm { MgCl }}{ }_{2}$ at $37^{\circ} \mathrm{C}$.

Results are expressed as means \pm standard error of the mean. A paired sample t-test was used to identify statistically significant differences. Significance was determined at $\mathrm{p}<0.05$.

\section{Results}

The pancreatic weights, enzyme concentrations and total pancreatic content of the enzymes are presented in Figs 1-7. Both CCK-OP injections and unheated soy flour feeding significantly increased pancreatic wet weight compared with appropriate controls. The pancreata in animals fed the toasted soy flour diet are slightly larger than those of animals fed regular chow. This probably reflects the fact that there is some residual tryptic inhibitor activity in the heat treated flour. With respect to the specific activity, the only significant alteration in the three enzymes studied was a fall in the concentration of glutathione-S-transferase. The decreases observed were $32 \%$ in the CCKOP treated animals and $14 \%$ in those fed raw soya flour diets as compared with control values. 


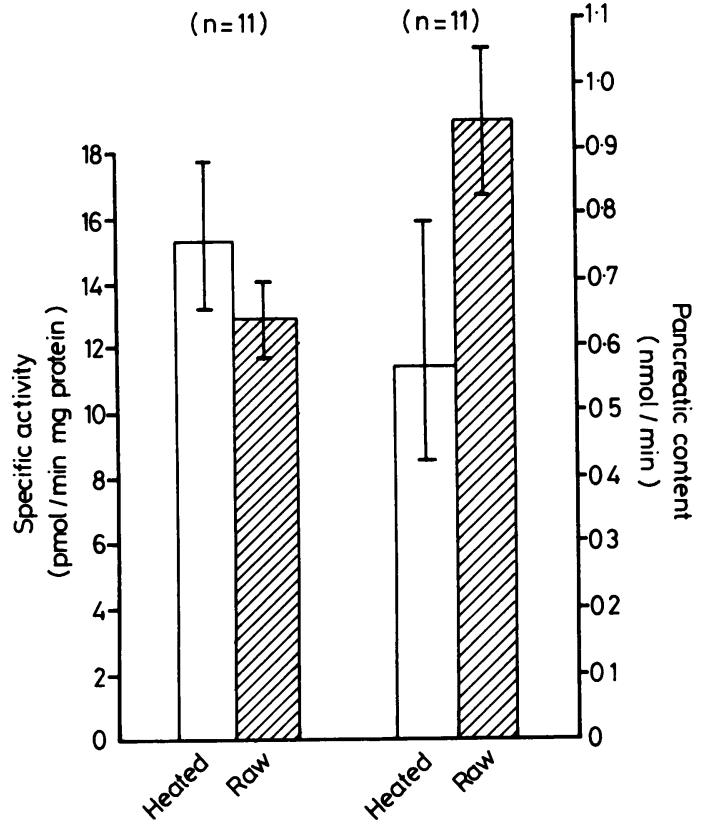

Fig. 3 Benzo(a)pyrene hydroxylase pancreatic concentration and total content soy flour feeding. * indicates $p<0.05$.

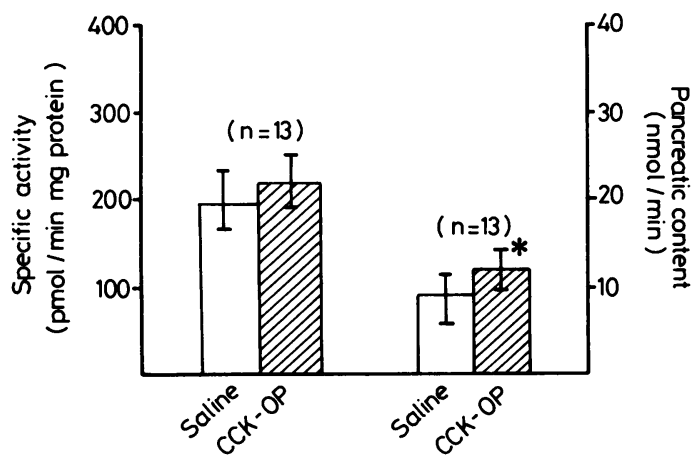

Fig. 4 Glucuronyl transferase pancreatic concentration and total content cholecystokinin-octapeptide treatment.

* indicates $p<0.05$.

\section{Discussion}

The causes of pancreatic cancer in man are presently unknown. Epidemiological evidence points to environmental factors as of considerable importance. ${ }^{14}$ Environmental chemical carcinogens in food and tobacco smoke must be considered among these factors. Experimental models of cancer of the pancreas have been most successfully developed in rodents for example, the azaserine induced car-

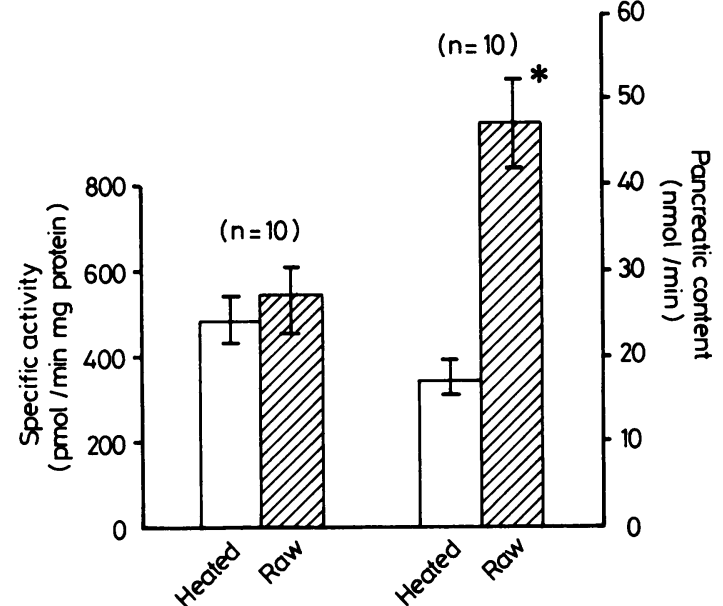

Fig. 5 Glucuronyl transferase pancreatic concentration and total content soy flour feeding. ${ }^{*}$ indicates $p<0.05$.

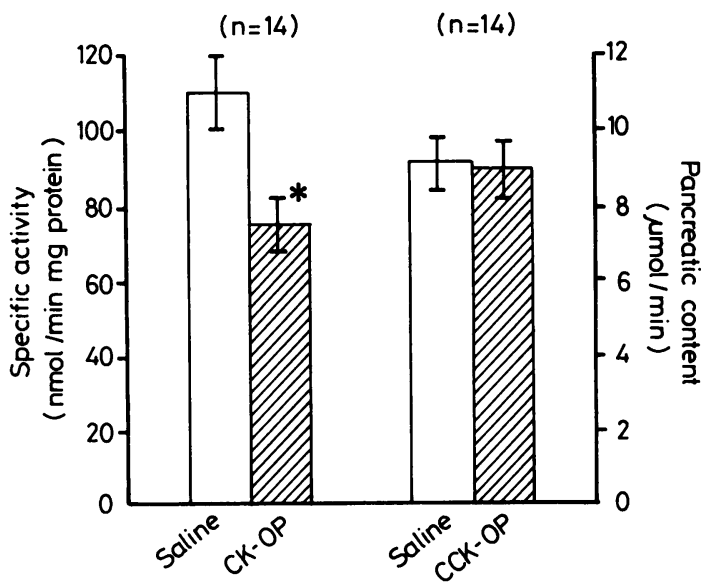

Fig. 6 Glutathione-S-transferase pancreatic concentration and total content cholecystokinin-octapeptide treatment.

*indicates $p<0.05$.

cinoma in rats and the nitrosamine induced model in hamsters (see reviews by Longnecker ${ }^{1516}$ ).

Most chemical carcinogens are procarcinogens, being inert until activated in the tissues by metabolic processes, chiefly oxidations. Thus the importance of xenobiotic-metabolising enzymes in target tissues is evident. Of particular interest is the fact that the activity of these enzymes can be induced by a variety of substances and conditions including exposure of the tissues to the substrates of these enzymes - for example, the polycyclic aromatic hydrocarbons.

Two general types of metabolic conversion of xenobiotics occur in tissues, namely, phase I reactions which add reactive groups to the molecule, for 


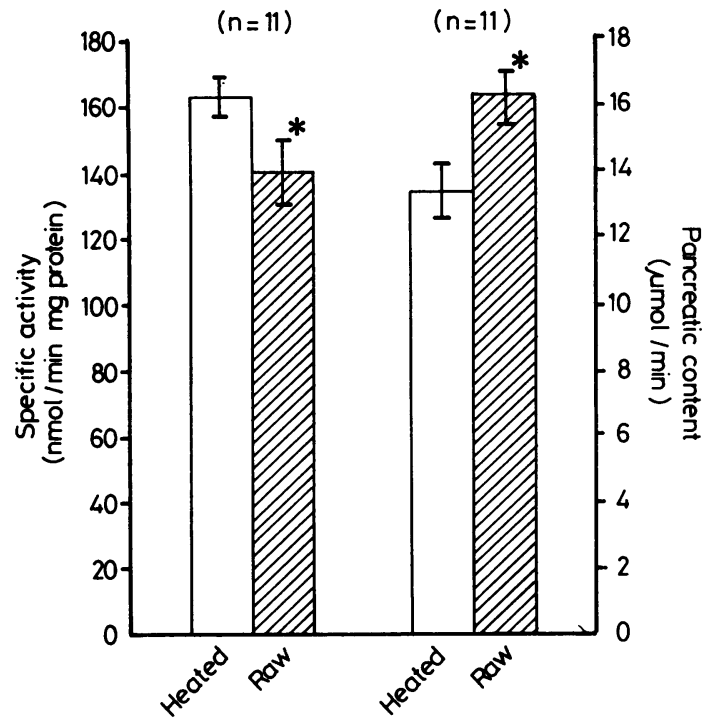

Fig. 7 Glutathione-S-transferase pancreatic concentration and total content soy flour feeding. ${ }^{*}$ indicates $p<0.05$.

example, oxidations, hydroxylations or acetylations, and phase II reactions which involve the conjugation of phase I products to form glucuronides, sulphates and glutathione conjugates (thio-ethers). The latter subsequently undergo further modification as glutamic acid and glycine are cleaved from the glutathione residue and, ultimately, acetylation of the cysteine residue yields mercapturic acid derivatives. In general, phase II reactions are regarded as detoxifying processes by which reactive, potentially toxic products of phase I reactions are converted into water-soluble, readily excretable products.

Of all tissues, the liver contains the greatest amount of enzymes concerned with phase I and II reactions but significant quantities of these enzymes are found in extrahepatic tissues. The pancreas is known to have measurable amounts of aryl hydrocarbon hydroxylase, a phase I enzyme system and glucuronyltransferase, a phase II enzyme. The concentration of these enzymes is much lower than those of the liver. ${ }^{16}$ On the other hand, glutathione-S-transferase, another phase II enzyme, is present in relative abundance in the pancreas of rats, being present at approximately $50 \%$ of the concentration of the liver enzyme. ${ }^{17}$

It has been shown that trophic influences on the pancreas, notably injections of CCK and soy flour feeding, act as cocarcinogens with chemical carcinogens such as $\mathrm{N}$-nitrosobis(2-oxopropyl)amine ${ }^{18}$ and azaserine. ${ }^{5}$ Furthermore, prolonged soy flour feeding can ultimately yield not only pancreatic hypertrophy but also adenomas and carcinomas. ${ }^{7}$ It is possible that the action of low levels of carcinogens in the diet is enhanced by trophic factors such as soy flour feeding.

Our results show that with the pancreatic hypertrophy associated with either CCK-OP or soy flour, no detectable change in aryl hydrocarbon hydroxylase or glucuronyl transferase specific activity (units/mg protein) occurs, but that a significant fall in glutathione-S-transferase can be demonstrated in both forms of pancreatic hypertrophy. There is evidence that the hypertrophy of soy flour feeding represents the effect of endogenous hypercholecystokininaemia,${ }^{34}$ thus these results may reflect the same phenomenon.

Although the explanation for the relative abundance of glutathione-S-transferase in the pancreas is not known it is possible that this enzyme represents a major detoxifying capacity of the pancreas. In a number of tissues, the concentrations of this enzyme, like other xenobiotic-metabolising enzymes, is increased by various agents present in the human diet, notably the butylated hydroxyanisoles. ${ }^{19}$ Agents inducing this enzyme might confer protection on the host against various xenobiotics. ${ }^{20}$ Conversely, conditions which depress the level of this enzyme may be of great significance in that they reduce the detoxifying capacity of a tissue. Our results, therefore, may offer one explanation for the carcinogenic activity of prolonged soy flour feeding in rats.

\section{References}

1 Barrowman JA, Mayston PD. The trophic influence of cholecystokinin on the rat pancreas. J Physiol (Lond) 1973; 238: 73-5p.

2 Temler RS, Dormond CA, Simon E, Morel B. The effect of feeding soybean trypsin inhibitor and repeated injections of cholecystokinin on rat pancreas. $J$ Nutr 1984; 114: 1083-91.

3 Green GM, Lyman RL. Feedback regulation of pancreatic enzyme secretion as a mechanism for trypsin inhibitor-induced hypersecretion in rats. Proc Soc Exp Biol Med 1972; 140: 6-12.

4 Liddle RA, Goldfine ID, Willaims JA. Bioassay of plasma cholecystokinin in rats: effect of food, trypsin inhibitor and alcohol. Gastroenterology 1984; 87: 5429.

5 Longnecker DS, Curphey TJ. Adenocarcinoma of the pancreas in azaserine-treated rats. Cancer Res 1975; 35: 2249-58.

6 Morgan RGH, Levison DA, Hopwood D, Saunders JHB, Wormsley KG. Potentiation of the action of azaserine on the rat pancreas by raw soya bean flour. Cancer Lett 1977; 3: 87-90.

7 McGuinness EE, Morgan RGH, Wormsley KG. Effect of soybean flour on the pancreas of the rat. Environ Health Perspect 1984; 56: 205-12.

8 Dallner $\mathrm{G}$. Isolation of rough and smooth microsomes - general. Methods Enzymol 1974; 31: 191-201. 
9 Tartakoff AM, Jamieson JD. Subcellular fractionation of the pancreas. Methods Enzymol 1974; 41-59.

10 Kandaswami C, O'Brien PJ. Effect of chrysotile asbestos and silica on the microsomal metabolism of benzo(a)pyrene. Environ Health Perspect 1983; 51 : 311-4.

11 Van Cantfort J, de Graeve J, Gielen JE. Radioactive assay for aryl hydrocarbon hydroxylase. Improved method and biological importance. Biochem Biophys Res Commun 1977; 79: 505-12.

12 Hoensch HP, Steinhardt HJ, Weiss G, Haug D, Maier A, Malchow H. Effects of semisynthetic diets on xenobiotic metabolising enzyme activity and morphology of small intestinal mucosa in humans. Gastroenterology 1985; 86: 1519-30.

13 Habig WH, Pabst MJ, Jakoby WB. Glutathione-Stransferases. The first enzymatic step in mercapturic acid formation. J Biol Chem 1974; 249: 7130-9.

14 Lin RS, Kessler II. A multifactorial model for pancreatic cancer in man. JAMA 1981; 245: 147-52.

15 Longnecker DS, Wiebkin P, Schaeffer BK, Roebuck
BD. Experimental carcinogenesis in the pancreas. Int Rev Exp Pathol 1984; 26: 177-229.

16 Longnecker DS. Experimental models of exocrine pancreatic tumours. In: Go VLW et al, eds. The exocrine pancreas: biology, pathobiology and diseases. New York: Raven Press, 1986: 443-58.

17 Black O Jr, Howerton BK. Glutathione-S-transferase activity in rat pancreas. $J$ Natl Cancer Inst 1984; 72: 121-3.

18 Howatson AG, Carter DC. Pancreatic carcinogenesisenhancement by cholecystokinin in the hamster-nitrosamine model. Br J Cancer 1985; 51 : 107-14.

19 Benson AM, Cha YN, Bueding E, Heine HS, Talalay P. Elevation of extrahepatic glutathione-S-transferase and epoxide hydratase activities by 2(3)-tert-butyl-4-hydroxyanisole. Cancer Res 1979; 39: 2971-9.

20 Sparnins VL, Yenegas PL, Wattenberg LW. GlutathioneS-transferase activity: enhancement by compounds inhibiting chemical carcinogenesis and by dietary constituents. J Natl Cancer Inst 1982; 68: 493-6. 